\title{
IDEOLOGIES AND THEORIES for youth practice work
}

RAMADIMETJE BERNICE HLAGALA AND CATHARINA SOPHIA DELPORT

\begin{abstract}
There are many youth workers who continue to design their interventions without any theoretical basis, despite a long history of youth work as a field of practice. The aim of this article is to present selected ideologies and theoretical frameworks underpinning youth work practice. These ideologies and theories, although predominantly borrowed from other disciplines, provide insight on how youth work should be practised.

Based on a thorough literature review, the authors have selected different theories and ideologies that youth workers, like other professionals, are expected to know, understand and to adapt to youth work practice. These theories are important and would serve as theoretical frameworks on which youth work interventions will be based and, thereby, provide youth workers with the means to predict and analyse the situations of young people from different viewpoints to enable the development of different strategies to address relevant problems.

The article concludes that theories and ideologies should be used as reference points, and youth workers mix and match different theories and ideologies depending on the nature of problem they are addressing at that particular time.
\end{abstract}

Key words: ideologies, theories, youth work, youth workers, youth, youth development

\section{Introduction}

A theory, ideology, approach, paradigm, perspective, broadly referred to in this article as ideology and narrowly as theory, is a system of ideas, beliefs and values, which are a perspective of looking at, and explaining a phenomenon or predicting something (Delport, Fouché and Schurink 2011). Theories are of utmost importance, particularly to members of the applied research community since they provide organised, interconnected explanations and predictions by placing the purpose and content of the phenomenon being studied into context; presenting the current state of knowledge regarding the research problem; and playing an invaluable role in unearthing the unexpected (May and Powell 2008). This is achieved through determining the policy 
environment: highlighting how the phenomenon is perceived, what is known about it, what aspects should be emphasised, and what actions or decisions ought to be taken.

By unpacking theories in this article, youth workers and other service providers in the youth development space, would know what guides youth work practice, anticipate future outcomes of their interventions, decide what to do next in each stage of the process, and explain why they acted the way they did when working with youth. Davies $(2011,59)$ argues that 'you can't ask to be seen to be providing a unique service without explaining how you are best placed to provide that service'. Theories, therefore, provide the practitioners with the rationale for their plans and work. They also provide them with more insight into the dimensions and complexity of the problems, give an understanding of the situation in a new and different light, link practitioners to the current research, benefit from what others have done, integrate and summarise what is known, and stimulate ideas (Anfara and Mertz 2006; May and Powell 2008; Turner 1986).

Like other practices underpinned by theories, these array of youth work theories and ideologies also arise out of, or are constructed by the attempts of others to describe practice, and could assist workers to organise their interventions in a clear manner (Broadbent 2006; Coulshed and Orme 2006). It is on that basis that this article looks at the benefits of using theories as a means to create capacity for youth workers and improve service delivery for the youth and their communities.

\section{Methods}

This article is based on literature research. Firstly, it describes the context within which ideologies and theories are developed. Secondly, it illustrates the application of ideologies and theories in analysing and addressing the situation of youth. Thirdly, it outlines the role of the youth worker. Finally, it offers guidelines by recommending the approach which youth workers should adopt in using these theories and ideologies in their day-to-day work with youth.

\section{Ideologies and theories}

May and Powell $(2008,2)$ argue that theories vary according to the cultural and intellectual traditions under which they are conceived and from which they draw their inspiration. The authors selected specific theories from three broad categories of ideologies relevant in studying society. The ideologies from which those theories were drawn are: the Functionalist or Structural Functionalist ideology, the Interactionist ideology, and the Conflict or Marxist ideology (Commonwealth Secretariat 2001 b). 
Although these theories were originally developed to focus on different aspects of human development, they have particular relevance for interventions in youth development settings, particularly in view of the fact that all professions are built on existing sciences (Chess and Norlin 1991; De Vos, Strydom, Fouché and Delport 2011). Each of the selected theories within the broad categories of ideologies is discussed briefly below.

\section{Functionalist or Structural functionalist Ideology}

Based on the work of Emile Durkeim (1858-1917), society, like an organism, is structured in many parts, each with its own function to the benefit of the whole society (Commonwealth Secretariat 2001b).

Firstly, the authors identified Humanistic theory as applicable to youth work field. On one hand, as one of the leaders in humanistic psychology, Abraham Maslow (19081970) saw the capable intervention of individuals in the course of their life's events as shaping and influencing their own beings (Burger 2009). He premised this from the point of view that individuals have the capacity to take action that will direct the course of their lives and enable them to cope with challenges. Similarly, Burger (2009), Vander Zanden (1993), as well as Chess and Norlin (1991) perceive people to have, within them, an ability to take charge of their lives and foster their own development, thus being responsible for their actions.

Abraham Maslow further identified a hierarchy of needs. According to him, people are motivated and strive to attain the needs in the high level of hierarchy, thus symbolising full development (Chess and Norlin 1991; Vander Zanden 1993). Hahn and Raley $(1998,388)$ defined youth development as 'an on-going growth process in which youth actively seek and are assisted to meet their basic personal and social needs to be safe, feel cared [for], valued, useful, be spiritually grounded and to build skills and competencies that allow them to function and contribute to their daily lives.' In postulating that needs are arranged and ranked from lowest (bottom) to the highest level (top) in a hierarchical order (Burger 2009; Chess and Norlin 1991), Abraham Maslow maintained that it is essential for the needs at the bottom of the pyramid to be satisfactorily met before meeting the needs at the next level. The authors list and discuss below, the hierarchy of needs, with the most basic needs (survival) located at the bottom of the pyramid, and the growth needs located at the top of the pyramid:

Physiological needs - are the physical needs such as hunger, thirst and sex drive. These ensure survival and are the most basic needs; 
- Safety and security needs - the need to feel safe, secure and out of danger, attainment of which gives an individual a sense of predictability, including a measure of order in their world;

- Social needs - are needs to belong, affiliate with others, and to experience acceptance, to love and be loved. When met, they enable an individual to form intimate relations in future;

- Self-esteem needs - are needs to achieve, to compete, gain approval and recognition, to respect oneself and others. When fulfilled, they make people feel confident, strong, useful and needed; and

- Self-actualisation needs - the need for beauty, order, simplicity and perfection, truth, justice and meaningfulness. These needs encourage an individual to realise his or her highest unique potential, thus becoming a fully functioning and goaloriented being.

According to this theory, the needs at the first two levels are the most basic and fundamental needs. The ones at the third and fourth levels are the psychological needs, and finally at the fifth level are growth needs that enable an individual to become more capable of 'becoming' (Burger 2009; Vander Zanden 1993). Even though Maslow said the needs at each level can be partially satisfied at any given moment, how well the lower needs are satisfied determines how much those needs influence behaviour (Burger 2009). Attainment of basic human needs at the fifth level - self-actualisation is consistent with 'positive youth development'. This has been defined as, 'a process which prepares young people to meet the challenges of adolescence and adulthood through coordinated, progressive series of activities and experiences which help them to become socially, morally, emotionally, physically and cognately competent' (Damon 2004).

This perspective is a turnaround for the practice, since Abraham Maslow did not relate the need to satisfy survival needs to any age level. Therefore, this means that a youth worker's role would be to involve, motivate and enable young people to participate in the process of meeting their needs, as this could be of utmost importance to their individual development (Chess and Norlin 1991). As a change agent, the youth worker should strive to unleash the young people's yet-to-be-tapped potential through meeting their basic human needs (Krauss and Suandi 2008). Against the above background, the authors are of the view that the environment ought to provide the individuals with second chance opportunities and space within which the identified needs can satisfactorily be met (Vander Zanden, 1993). They concluded that one of the key roles of youth workers is to point out where such opportunities exist for young people and to facilitate their optimal use in meeting their needs at different levels. This would also include attaining the ultimate development of self-actualisation/ realisation. 
Secondly, in recognising that the community within which young people reside forms part of their immediate environment, the authors identified the Community Youth Development theory. This theory highlights the importance of strengthening communities, so that they in turn can be functional in nurturing and supporting young people, thus ensuring sustainable development (Benson and Pittman 2001; Villaruel, Perkins, Borden and Keith 2003; Wheeler 2000). The emphasis is on empowering and developing young people who are, in turn, expected to contribute positively to development of the communities that have built them (Lerner, Brentano, Dowling and Anderson 2002). Failure to empower and develop young people could result in their inability to perform this historic task.

Various authors indicate that the way to improve the lives of individual young people is to improve the communities in which they live by making them better places (Villaruel et al. 2003). This theory, therefore, attempts to involve young people in improving their lives and their own development as well as that of their communities. In that regard, the asset-rich communities are seen to be giving young people the resources needed to build and pursue healthy lives that make a productive contribution to self, family and community (Lerner et al. 2002). Therefore, the assumption that 'healthy communities will nurture and support healthy families and individuals' holds some truth (Villaruel et al. 2003). This will result in a cyclic pattern where supported individuals will, in turn, contribute towards strengthening their own communities and thus creating a better environment for the generations to come. The emphasis of this theory is on helping young people see value in a caring society; and for society to see the value of investing in youth (Peteru 2008).

It is for these reasons that converging youth and community development is necessary, taking into account factors that have weakened the African value of interdependence once available to young people by replacing it with the western value of individualism (Arnett 2001). These changes can be attributed to factors such as changed community structures (nuclear versus extended family); changed cultural practices (collectivism versus individualism); changed family circumstances (involving working parents and disorganisation). According to the Commonwealth Secretariat (2001 b), these changes would have an impact on the nature and content of young people's development, how they react to available opportunities and services, and their position in society. From this theory, the community function of reinforcing the socialisation role of the family could also be affected (Commonwealth Secretariat, 2001b). The implication is that young people would no longer have the same support from their communities as they did in the past.

Evidently in light of this, the role of the youth worker could be to do the following: ensure that both changed structures and practices respond to the needs of young people (South African Youth Workers Association 2001); inculcate a sense of historical 
continuity by helping young people to remain connected to their communities through understanding how they came to be who, what, and where they are now (Krauss and Suandi 2008); and create an enabling environment within which young people can thrive by ensuring that they acquire personal and social assets to strengthen themselves, their community support structures, and consequently to help them to adapt to the changing environment (National Research Council and Institute of Medicine 2002).

It is significant that the community youth development theory views youth work as part of community development and reform (Broadbent 2006). Working with youth and communities as partners in effecting changes that empower both parties whilst fostering continuous engagement and connections is important for mutual benefit (Broadbent 2006; South African Youth Workers Association 2001; Krauss and Suandi 2008).

\section{Interactionist Ideology}

The interactionist ideology pronounces individuals and groups as actors in society and attaches social meaning and significance to their actions. Thus, through interaction with others and the environment, individuals develop awareness and build a concept of themselves (Commonwealth Secretariat 2001b). The authors selected the Positive Youth Development and Social Systems theories as most relevant to youth work. These theories focus on the way individuals and groups interact with each other in everyday life (Gilbert and Specht 1981; May and Powell 2008).

The Positive Youth Development Theory contrasts with other theories that focus on problems experienced by young people as they grow up. It looks at their capabilities, developmental potentials, and increases their thriving behaviours rather than their deficiencies (Damon 2004; Peterson 2004; Peteru 2008). By enforcing these traits, an individual's assets are built, thus protecting him or her from health-compromising behaviours, whilst enhancing the opportunity for positive developmental outcomes and building resiliency in an effort to counter problems (Benson 2002; Peteru 2008). This theory addresses young people from a balanced and positive perspective, as it views them as resources rather than problems. According to Lerner et al. (2002), this theory stresses that positive youth development emerges when the potential plasticity of human development is aligned with developmental assets. It conceives of young people from a strength-based position by recognising that their unending potential is consistent with their strengths (Benson 2002; Damon 2004; Peterson 2004).

The Positive Youth Development theory is based on the five Ps identified by Villaruel et al. (2003): 
- Possibilities and preparations - This asks, what opportunities are available for youths in communities? This refers to creation of opportunities that will develop young people in every part of their lives either physically, intellectually, morally, spiritually, socially or emotionally (Merton and Payne 2000). Pittman (1993) asserts that programmes should provide opportunities for youth to develop in a variety of ways and help them to avoid risk factors that interfere with good outcomes.

- Participation -- Do we know how youth are spending their out-of-school time? This approach aims to understand, educate and engage youth (Damon 2004). It is essential that the young not only identify, but also accept their responsibilities as individuals, citizens and group members. Youth participation in decision making gives them voice by shaping the course of their development through encouraging them to take part in influencing processes, exposing abuses of power and realising their rights (Brown 2004; Merton and Payne 2000; Peterson 2004; South African Youth Workers Association 2001; United Nations Convention on the Rights of a Child 1989 in Peteru 2008).

- People -- Who are the people interacting with youth daily? Who is in charge of youth programmes? Merton and Payne (2000) identified youth workers to be in charge of youth programmes. On the other hand, Benson and Pittman (2001) highlighted the investment and involvement of public and private sectors and the wider community as crucial for youth development (Benson 2002).

- Places and pluralism -- What resources are available for young people? How can they be accessed? This involves evaluating the resources that young people can use to meet their needs and maximise their potential (Merton and Payne 2000). This will entail checking availability of opportunities, resources and support systems necessary for the development of young people (Benson and Pittman 2001).

- Partnership-- Are young people partners in planning and implementing programmes that affect them? A sense of ownership could be fostered by engaging them to become proactive in their development and also to involve them in decisionmaking processes (Benson 2002).

It is evident that this theory is consistent with the definition of youth development as cited in this article, because it considers the underlying causes of problem behaviours and stresses positive outcomes for the youth. These outcomes are known as the five Cs and include competence, confidence, character, connection and contribution or caring (Lerner et al. 2002; Villaruel et al. 2003; Wheeler 2000). The Positive Youth Development theory is also compatible with both the right-based and sustainable livelihood approaches, because it is person driven, holistic, strength-based and seeks to bring about a long lasting impact (Commonwealth Secretariat 2001 b). According to Merton and Payne (2000), it directly contributes towards achievement of the purposes of youth work by identifying and developing young people's capacities - physical, moral, spiritual, social and emotional; identifying and accepting young people's 
responsibilities as individuals, citizens and group members; and evaluating the context within which young people live and act.

It is significant that, even though the Positive Youth Development theory applauds involvement and participation of young people in development processes, it acknowledges this effort as being insufficient and that more effort should be made for youth to channel their energies in 'positive directions' as this would make them 'responsible' whilst encouraging institutional support (Peteru 2008, 28). This theory, therefore, motivates young people (regardless of their problems) to use their potential to the full and to seek and receive support from the human environment (family, peer group, school and community).

As in humanistic and community development theories, according to Borden, Craig and Villaruel (2004); Brown (2004); Krauss and Suandi (2008); and Merton and Payne (2000), the roles of a youth worker in the context of Positive Youth Development theory are to do the following: Create an enabling environment to produce positive young people who can contribute to their families, communities, and society; build the capacity of individuals and groups to develop a stronger sense of identity and belonging; put young people and their concerns at the centre by recognising their current livelihood strategies, social environment and their adaptability; and ensure that young people contribute to the development of the community or society in which they live.

By implementing Positive Youth Development theory, young people will see themselves and be perceived by others as in a position of strength. They can be seen as resources, experts in their own development with capacities and abilities to make meaningful contributions rather than being problematic and having deficits (Hahn and Raley 1998; Krauss and Suandi 2008). If interventions are strength-based, they will help young people to further develop an orientation to contribute to their communities and society (Lerner et al. 2002; Wheeler 2000). The youth worker's role in this regard would be to 'help the youth to attach positive social meaning and significance to their actions' (Commonwealth Secretariat 2001b).

Another theory that the authors selected within the interactionist ideology is Social Systems theory. This is a holistic theory, based on the basic assumption that 'the whole is more than the sum of its parts' (Anfara and Mertz 2006; Chess and Norlin 1991). It was developed largely in response to the need for different disciplines to analyse the complex interactive situations in which various system consisting of smaller elements or subsystems and larger suprasystems, impinge upon the life of an individual (Shaffer and Kipp 2009). How these systems interact must be understood. This theory further views an individual as an organism and a member of society (Coulshed and Orme 2006; Lerner et al. 2002). In this context, development is seen as a product of interaction 
between the individual and various systems in which an individual may or may not be an active participant. The role played by these systems in shaping an individual's behaviour must be scrutinised and analysed as a means towards ensuring an adaptive process of reorganisation and growth. Importantly, the role played by the environment in the development process should be given equal attention (Benson 2002; Shaffer and Kipp 2009; Garfat 2003; Lerner et al. 2002).

When the Social Systems theory is applied to the field of youth work, the youth workers' role will be to analyse the interactions between young people and their situations. They will also analyse the way youth are affected by these interactions with the aim of detecting whether or not the individual youth will develop positively or negatively (Benson 2002; Lerner et al. 2002). Therefore, the effort to change outcomes will consequently not only be directed at young people themselves, but also at the systems in which young people are caught up, thus taking into consideration the full context of a young person's life (Davies 2004; Lerner et al. 2002; Wheeler 2000). In support of this view, Garfat $(2003,71)$ stated that, 'when working with youth on particular behaviour, youth workers can often get lost inside the immediate dynamics and ignore the much more powerful and pervasive influences that are really within their sphere of ability'. It means that youth workers ought to analyse the causal factors that hinder development of young people and avoid the greater likelihood of focusing on influences that are on the surface, as those could probably be symptoms.

It also means that, in as much as it is important to understand young people, the various kinds of systems that may have influence on them should equally be studied and clearly understood. Various authors identified the following types of systems (Shaffer and Kipp 2009; Garfat 2003; Lerner et al. 2002):

- Intrapersonal system -- This refers to a system within the individual. It involves factors within a person that have an influence on them, for example, attitude, perception, emotion, cognition, competencies and skills. These factors develop gradually over time as a result of socialisation and experience and have an influence on the individual person. At this level, changing the self to support the systems and/or altering the systems to support the self, requires skills on the part of the individual to regulate the relations for development to occur.

- Interpersonal or micro or socio cultural system - This is a system between an individual and small other systems, for example, dyads, family, friendship group, peer group, work group and church. It involves patterns of activities, roles and interpersonal relations that an individual has with other systems. This developmental system stresses the need to strengthen linkages between developing individuals and their changing family and community settings, hence Lerner et al. (2002) mentioned the significance of involving a young person in healthy, positive relations with other systems to achieve positive development; 
- Mesosystems -- These refer to interrelations between two or more systems such as neighbourhood, educational and career opportunities, local political environments, public policy and economic systems. These factors encourage an individual to become an actor within the community and, consequently, be of value and usefulness within it. The presence or lack of these factors in the environment within which an individual lives, affects the way they turn out.

- Socio-economic or macrosystems -- These entail broader systems that do not involve the developing person as an active participant, for example, socioeconomic conditions, political changes, national issues and environmental concerns that have impact on the well-being of young people. Although these are external factors in the environment and are usually beyond the control of an individual, they have far reaching implications. For example, the socio-economic background of an individual youth may influence the availability of opportunities for education and in turn affect the employability of that individual.

From the beginning of existence, humans have been linked to these systems for survival and the state of these systems affects and influences the development of an individual (Commonwealth Secretariat $2001 \mathrm{~b}$ ). It is, therefore, critical that positive relations are fostered through ensuring that the systems in the social environment respond to the individual's needs, whilst promoting their productive functioning and healthy development. Such development enables young people to become adults, who would ideally contribute to self and context in a way that maintains and perpetuates the social order and advances social justice (Lerner et al. 2002).

The authors are of the opinion that the Social Systems theory can be used effectively in youth work, as it would enable youth workers to identify and engage various systems in the process of development and allow each of them to play their role, thus contributing maximally to development of the youth. The relevance of using this theory when dealing with young people cannot be ignored, especially since it promotes collaboration across various systems that have the common purpose of building the developmental strengths of young people (Benson, 2002 as cited in Lerner et al. 2002).

\section{Conflict or Marxist Ideology}

The conflict or Marxist ideology by Karl Marx (1818-1853) does not see society as a well-functioning organism. Instead it argues that there is inevitable change and conflict in society as individuals and groups struggle over scarce economic resources (Commonwealth Secretariat 2001b). Here, the authors selected the Psychosocial and Advocacy theories as applicable to the youth work field. Both of these theories aim to create social change in the individual, evolving and influencing groups in the community and/or society. The intention is to bring changes through reform, policy, 
social relations and political action (Broadbent 2006; Commonwealth Secretariat 2001 a; Gilbert and Specht 1981; Krauss and Suandi 2008).

The Psychosocial theory by Erik Erikson (1950) was selected, because of its focus on the importance of early experience in personality growth as well as on current and future experiences (Commonwealth Secretariat 2001b). This theory provides a helpful frame of reference, as it identifies and analyses the eight psychosocial stages of development determined by the human genes across the life span. It is built on the idea that emotional social growth progresses through different stages, each with its own unique ego accomplishments (Commonwealth Secretariat 2001 b; Vander Zanden, 1993).

This theory is based on the premise that the process of living from birth to death consists of an individual working his or her way from one stage of development to the next (Erickson 1964 in Osei-Hwedi, Mwanza and Mufune 1990). It argues that social problems are a result of unsuccessful negotiation of what happens in each stage. Similarly, young people negotiate a series of transitions, including from primary to secondary education, school to work and family home to independent living (South African Youth Workers Association 2001). The conflict occurs when social problems are experienced owing to unsuccessful negotiation of what happens in each stage. Instead of defining young people in terms of the problems they are experiencing, proponents of this theory explore the potential conflict that may arise in each developmental stage, and determine the way in which that would significantly affect the manner in which an individual negotiates the crisis or facilitates a smooth transition (Davies 2004). "The individual is confronted in each of Erikson's eight stages with a major crisis that must be successfully resolved if healthy development is to occur" (Vander Zanden, 1993). The following psychosocial stages with specified approximate ages are applicable to this theory:

- Stage 1 -- Trust versus Mistrust (Birth --18 months): This stage is characterised by the need for regular, reliable, and loving care that may lead to the development of trust. Failure to provide such care may result in a sense of mistrust.

- Stage 2 -- Autonomy versus Shame and Doubt (18 months -- 3 years): This is where children develop a sense of separate identity and independence that may also lead to anxiety about separation, a sense of inadequacy, and/or feelings of shame and doubt.

- Stage 3 -- Initiative versus Guilt (3--6 years): At this stage, children plan and act independently. If they are not allowed to initiate, experiment and implement their plans, they may feel guilty. This stage is critical for the development of the conscience.

- Stage 4 -- Industry versus Inferiority (6--12 years): Interaction with peers and significant others is important in development of self-esteem, but the lack thereof may lead to feelings of inferiority. 
- Stage 5 -- Identity versus Role confusion (12--20 years): Identity formation is a critical task of youth development or the youth will remain confused about the role they ought to play as adults.

- Stage 6 -- Intimacy versus Isolation (20--35 years): The emphasis is on achieving balance by forming close and intimate relations. The difficulty of engaging in such relationships may lead to isolation.

- Stage 7 -- Generativity versus Self-absorption or Stagnation (35 years -- retirement): This involves commitment to help and to provide for the next generation, care for other people, and the need to pass on knowledge and traditions. If this need is not met, a feeling of stagnation or being obsessed with oneself could develop. Stage 8 - Integrity versus Despair (retirement): Integrity refers to realistic acceptance of one's life as it is (accepting successes/ strengths as well as failures/ weaknesses). In contrast, despair implies bitter regret and lack of acceptance of one's life. This stage involves looking back at one's life and then taking stock of one's failures and successes.

Of relevance to young people in this theory is what happens in stages 5, 6 and 7 . The authors identified these stages, because they cover the youth period ranging between 14 and 35 years. In stage 5 (14--20 years), the young experience identity versus identity confusion when they strive to establish their own separate identity through work, peer relationships and separation from parents when beginning to have their own views of themselves (Benson 2002; Commonwealth Secretariat 2001 b). In stage 6 (20--35 years), the young person experiences intimacy, failing which could lead to isolation. Finally, stage 7 (35 years) is on generativity versus stagnation. This is where older young people yearn to provide for the next generation and failure to do so could lead to obsession with oneself.

According to Hamacheck (1988) and Vander Zanden (1993), since each stage is a critical building block for the next or subsequent stage, the manner in which it is negotiated can either enhance or hamper the ultimate personality development. The successful negotiation of each stage leads to development of new social capabilities and societal approval; whereas unsuccessful negotiation leads to a psychosocial crisis that may produce tension (Commonwealth Secretariat 2001 b).

Whatever the outcome, a person's general orientation to the succeeding stages could be influenced. Therefore, when working within this model, it would be important to help young people to negotiate their current stages in preparation for the future, and also to help them deal with the barriers that develop as a result of their early experiences (Hamacheck 1988; Vander Zanden 1993). This is unavoidable since, traditionally, families (to be more specific, adults) as the primary socialisation agents, have the responsibility 
of supporting and assisting their younger members (Krauss and Suandi 2008). However, with the increase in family breakdown, changes in community structures, and erosion of traditions, these traditional methods have become less effective in facilitating young people's successful transition to adult life (Commonwealth Secretariat 2001a; Krauss and Suandi 2008), because the older members have now lost their once-powerful influence on socialisation. Therefore, the need for alternative forms of support for young people such as professional help from youth workers becomes critical.

The youth workers, in undertaking their roles, would be supplementing families by providing the much needed services to the youth such as developing and providing programmes, helping them to negotiate the tasks applicable to their stage at any given point in time, and ensuring that they successfully pass through each stage and/ or deal with the difficulties experienced in handling the tasks designated to them in previous stages of their development (Commonwealth Secretariat 2001a). The youth workers may further help young people to correct or rectify whatever problems have arisen in the course of their development (Meyer, Moore and Viljoen 1997).

The Advocacy theory is based on a pluralist view. It sees society's social problems as emanating from inequitable distribution of power and resources (Commonwealth Secretariat 2001 a). It is argued that the struggle for social resources is caused by groups that are more powerful than others. This theory sees young people as being involved in a struggle for and against equalising power relations and control exerted over young people by adults (Peteru 2008). This struggle between generations manifests itself in problems such as lack of respect for young peoples' rights and society's failure to protect young people's rights (Commonwealth Secretariat 2001a; Commonwealth Secretariat 2001b).

It is on this basis that the authors concluded that youth workers and other service providers in the youth development space, have to play the role of advocates who can act on behalf of and with these young people to 'create conditions for them to discover themselves and give meaning to their lives' (South African Youth Workers Association 2001; Krauss and Suandi 2008). The interventions used by proponents of this theory include creating opportunities for the youth, empowering them, and advocating responsive systems (Commonwealth Secretariat 2001 b). In this regard, the youth workers could also serve as a compass that can help direct the youth to gain control of their lives and to become socially responsible persons.

The significance of this theory is heightened when the youth optimally use the support systems around them such as families, professional agencies, and other institutions of socialisation (Gilbert and Specht 1981). 


\section{Concluding remarks}

Although the above theories and perspectives laid an important foundation for guiding youth work practice, they will not result in a 'recipe' book or manual for youth workers. The authors agree with the extensive review of literature that no single theory can be used to explain a specific phenomenon (Shaffer and Kipp 2009; Turner 1986). With this view in mind, an 'eclectic' approach that combines various theories is recommended to be used to develop intervention strategies. The mixing of theories and selection of the most appropriate and relevant aspect that fits the specific problem situation, would help youth workers to respond to the broad and varied needs of young people.

The demand for feasible solutions that are responsive to young people's needs and problems could provide an opportunity for youth workers to become champions in youth development space to conceptualise and execute practical strategies that are based on replicable theory-based interventions. Such theories should aim to change the social conditions of young people and/or of the systems to which they belong. This could make them morally committed agents of their own healthy development and could also positively enhance the lives of other people in society (Lerner et al. 2002). The theories are a sure way of connecting youth workers with other service providers and helping them understand and relate better. This is essential, given that 'youth workers work with others inside and outside the sector' (Davies 2011, 59).

\section{About the authors}

Doctoral Graduate, University of Pretoria - RSA, Department of Social Work and Criminology. bernice@po.gov.za.

Associate Professor, University of Pretoria - RSA, Department of Social Work and Criminology. rina. delport@up.ac.za.

\section{References}

Anfara, V. A. and N. T. Mertz. 2006. Theoretical frameworks in qualitative research. United States of America: Sage.

Arnette, J. J. 2001. Emerging adulthood: what is it, what is it good for. Child Development Perspectives. 1 (2), 68--73.

Benson, P. L. 2002. Adolescent development in Social and Community context: a program of research. In R. M. Lerner, C. S. Taylor and A. von Eye, ed. Pathways to positive development among diverse youth: new directions for youth development, 123--148. USA, California: Wiley Periodicals.

Benson, P. L. and J. K. Pittman. 2001. Trends in youth development: visions, realities and challenges. USA, Boston: Academic Publishers. 
Borden, L. M., D. L. Craig and F. A. Villaruel. 2004. Professionalising youth development: the role of higher education. New directions for youth development 104: 75--85.

Broadbent, R. 2006. Establishing good practice in planning and youth work practice. Commonwealth Youth and Development 4 (1), 49--62.

Brown, N. A. 2004. Promoting adolescent livelihoods. Commonwealth and Youth development 2 (2), 5--23.

Burger, J. M. 2009. Biological approach. In Department of Psychology, University of Johannesburg. Introduction to field in psychology. Johannesburg: McGraw-Hill Education.

Chess, W. A. and J. M. Norlin. 1991. Human behavior and the social environment (2nd ed.). USA: Allyn and Bacon.

Commonwealth Secretariat. 2001 a. Diploma -- Youth in Development Work module. Working with young people in their communities. London: Commonwealth Secretariat.

Commonwealth Secretariat. 2001 b. Diploma -- Youth in Development Work modules. Principles of young people and health. London: Commonwealth Secretariat.

Coulshed, V. and J. Orme. 2006. Social work practice (4th ed.). China: Palgrave Macmillan.

Damon, W. 2004. What is positive youth development - The Annals of American Academy of Political and Social Science, 59, 13--24.

Davies, M. 2004. The Blackwell Encyclopaedia of Social work. United Kingdom: Blackwell Publishing.

Delport, C.S. L., C. B. Fouché and W. Schurink, W. 201 1. Theory and literature in qualitative research. In A. S. de Vos, H. Strydom, C. B. Fouché and C. S. L. Delport, ed. Research at the grass roots for the social sciences and human service professions, 297--306 (4thed.). Pretoria: JL Van Schaik.

De Vos, A. S., H. Strydom, C. B. Fouché and C. S. L. Delport. 2011. Building a scientific base for the helping professions. In A. S. de Vos, H. Strydom, C. B. Fouché and C. S. L. Delport, eds. Research at the grass roots for the social sciences and human service professions, 507--513 ( $4^{\text {th }}$ ed.). Pretoria: JL Van Schaik.

Garfat, T. 2003. A child and youth care approach to working with families. Child and Youth Care Services, 25 (1/2), 7--37.

Gilbert, N. and H. Specht. 1981. The emergence of social welfare and social work. (2 ${ }^{\text {nd }}$ ed.) Illinois: F.E. Peacock Publishers, Inc.

Hahn, A. B. and G. A. Raley. 1998. Youth development on the path towards professionalisation. Non-profit management and leadership 8 (4), 387--401.

Hamacheck, D. E. 1988. Evaluating self-concept and ego development within Erikson's psychosocial framework: a formulation. Journal of Counselling and Development 66 (8), 354$-360$.

Krauss, E. S. and T. Suandi. 2008. The potential of youth workers as facilitators of values formation and development. Commonwealth Youth and Development 6 (1), 2--14.

Lerner, R. M., C. Bretano, E. M. Dowling and P. M. Anderson. 2002. Positive youth development: thriving as the basis of personhood and civil society. In R.M. Lerner, C.S. Taylor and A. von Eye, ed. Pathways to positive development among diverse youth: new directions for youth development, 11--34. USA, CA: Wiley Periodicals.

May, T. and J. L. Powell. 2008. Situating social theory (2nd ed.). England: Open University Press.

Merton, B. and M. Payne. 2000. Louder than words: youth work and learning for sustainable development. UK: Youth Work Press. 
Meyer, W. F., C. Moore and H. G. Viljoen. 1997. Personology: from individual to ecosystem. Johannesburg, South Africa: Heinemann Higher and Further Education.

National Research Council and Institute of Medicine Report. 2002. Community programs to promote youth development. USA.

National Youth Commission. 1997. National Youth Policy. South Africa, Pretoria.

Osei-Hwedi, K., L. Mwanza and P. Mufune. 1990. Youth and community work practice. Lusaka, Zambia: Multimedia Publications.

Peterson, C. 2004. Positive development: realising the potential of youth. USA, Washington, D.C.: National Press Club.

Peteru, P. S. 2008. Youth development: a Pacific context. Commonwealth Youth and Development 6 (1), 23--35.

Pittman, K. 1993. Stronger staff stronger youth conference. Washington, D.C: Center for Youth Development and Policy Research.

Shaffer, D. R. and K. Kipp. 2009. The context of development. In Department of Psychology, University of Johannesburg. Introduction to fields in psychology. Johannesburg: McGraw-Hill Education.

South African Youth Workers Association. 2001. Youth work policy. South Africa.

Turner, F. 1986. Social work treatment - Interlocking theoretical approaches (3rd ed .). New York: Macmillan.

Vander Zanden, J. W. 1993. Human development (5 $5^{\text {th }}$ ed.). USA: McGraw-Hill.

Villaruel, F. A., D. F. Perkins, L. M. Borden and J. Keith. 2003. Community youth development: programs, policies and practices. London: Sage.

Wheeler, W. 2000. Emerging organisational theory and the youth development organisation. Applied developmental science 1(4), 47--54. 